\title{
INVARIANTES EN LA EVOLUCIÓN E IDENTIDAD TERRITORIAL DEL PAISAJE DE HUERTA TRADICIONAL DE LA VEGA BAJA DEL RÍO SEGURA: 1929-2010
}

\author{
Clara García-Mayor \\ Departamento de Edificación y Urbanismo. Universidad de Alicante \\ magarma@ua.es
}

\section{RESUMEN}

A partir del estudio de la evolución de la Huerta de la Vega Baja del Río Segura, en Alicante, se identifican cuatro invariantes que dotan de coherencia e identidad a este territorio: la red de riego-avenamiento, la red de caminos, los asentamientos y los cultivos. El análisis de la organización estructural, la métrica, las características y la evolución de cada uno de ellos, constata su dependencia funcional y espacial, así como la relevancia que adquieren en la transformación de la precepción de este paisaje singular.

Palabras clave: Invariantes del paisaje, Caracterización del paisaje, identidad territorial, Huerta Vega Baja, río Segura.

\section{ABSTRACT}

From the study of traditional Huerta landscape evolution at Vega Baja of the Segura River, in Alicante, four invariants are identified giving coherence and identity to this territory: the irrigation-drainage canals system, road and paths network, settlements and crops. Analysis of their structural organization, metric, specific characteristics and evolution of each of them, determine their functional and spatial interrelation, as well as the relevance acquired in transforming this unique landscape's perception.

Keywords: landscape invariants, landscape character, territorial identity, Huerta Vega Baja, Segura River.

Fecha de recepción: junio 2015.

Fecha de aceptación: marzo 2016. 


\section{INTRODUCCIÓN}

La Huerta de la Vega Baja del Segura es un área claramente delimitada, resultado de la organización y adaptación del territorio, con coherencia formal y clara estructura espacial. Históricamente, su población se ha adaptado a las características físicas del medio, desarrollando, a partir de la experiencia, reglas específicas para el reparto del agua de riego o para medir el suelo, entre otras, que han equilibrado durante siglos la dinámica entre las condiciones extremas climáticas y medioambientales y el espacio de oportunidad y fertilidad que es esta llanura aluvial (Canales, 1995). Por todo ello, es un paisaje cultural que podemos calificar de valor singular, dada sus especificidades únicas frente a otras áreas similares.

Este enclave es un paisaje de base agrícola, directamente articulado con la Huerta de Murcia, que presenta rasgos similares a otras vegas del arco mediterráneo, pero también se identifican algunos atributos diferenciales que suponen un valor añadido desde el punto de vista de la diversidad paisajística y riqueza cultural. Esta Huerta conforma una unidad territorial reconocida en estudios geográficos, históricos y medioambientales, entre otros. Como prolongación natural de la Huerta este de Murcia, forma parte del mismo sistema de cuenca, tanto hidrográfica como estructural, del valle que recorre el río Segura en su último tramo desde la contraparada o Azud Mayor, en Murcia, hasta la desembocadura en la Gola de Guardamar del Segura, al sur de la provincia de Alicante. El ámbito de estudio que aborda la presente investigación se circunscribe al área del valle correspondiente a la comarca del Bajo Segura en Alicante, desde la denominada Vereda del Reino, divisoria entre la Región de Murcia y la Comunidad Valenciana, hasta la costa mediterránea. Pese a que los rasgos definitorios de un paisaje no tienen por qué estar condicionados por los límites administrativos geopolíticos; la existencia de estas divisorias sí que concretan diferencias derivadas de la gestión del territorio, planeamiento urbanístico o criterios de inversión. Este factor determina, no sólo la percepción y comprensión del lugar, sino que influye en las propias aspiraciones de la población local.

Desde su origen, la transformación de tierras de almarjal en parcelas de cultivo, se consolida y va ampliándose a lo largo de los diez siglos de historia documentada (De Gea, 1995) gracias a la alta fertilidad de las tierras y al consistente sistema de riego-drenaje único, que determina la organización parcelaria del llano aluvial, junto con la red caminera y el sistema de asentamientos tradicional. Los patrones de distribución de las teselas de huertos, la ocupación y los usos del suelo, así como las escalas de los elementos que configuran el espacio vital de la sociedad que lo habita, añaden complejidad a la interpretación del lugar y determinan su percepción.

Estos paisajes de Huerta -Murcia y Vega Baja- surgen de la lucha permanente de la sociedad que habita el llano aluvial con las dificultades geomorfológicas, climatológicas y el régimen irregular del río Segura; cuyo estiaje prolongado durante meses de déficit hídrico, pasaba a desbordarse por efecto de las riadas, como cara y cruz de una misma moneda: motor de riqueza, fertilidad y diversidad productiva, a la vez que causa principal de devastación de cosechas y construcciones (Andrés 2011; Canales, 1993; Calvo García-Tornel, 1972). Por tanto, desde tiempo inmemorial, las decisiones de organización del territorio y la estrategia de ocupación del suelo vinieron marcadas por la búsqueda 
de soluciones que minimizaran los efectos adversos de las avenidas. Dados los estragos originados por los episodios de crecida, este río ha sido etiquetado como uno de los ríos más controlados de Europa (Gómez y Grindlay, 2008), con un cauce totalmente alterado por las diferentes transformaciones a las que ha sido sometido para el control y regulación del mismo.

El presente artículo estudia la evolución del paisaje en el curso bajo del río Segura, buscando determinar qué elementos permanecen como invariantes, manteniendo así la esencia identitaria de este entorno tradicionalmente agrícola; así como detectar qué factores de cambio se han introducido, de manera que modifican la lectura del mismo. A partir de los resultados extraídos del estudio de la evolución histórica sobre la fotografía aérea, se identifican los puntos de inflexión más relevantes en la dinámica territorial del ámbito de trabajo entre 1929 y 2010, que es la horquilla temporal en la que la fotogrametría se utiliza como herramienta documental y de planificación territorial. Estos análisis forman parte de una investigación centrada en la definición de dichos elementos identitarios del paisaje, su parametrización y la determinación de factores de cambio que transforman la interpretación del mismo.

\section{LÍNEA TEMPORAL Y EVOLUCIÓN TERRITORIAL}

Debido a los estragos que las crecidas y desbordamientos del río producían, de manera cíclica, en los tramos medio y bajo del Segura; desde su constitución a principios de siglo XX, la Confederación Hidrográfica del Segura (CHS) abordó la búsqueda de soluciones y la programación de inversiones a realizar encaminadas al control de las avenidas, utilizando la fotografía aérea como instrumento para la toma de decisiones (Grindlay y Hernández, 2007). Por este motivo se dispone de un documento de valor incuestionable que es el vuelo realizado en 1929, encargado a la Compañía Española de Trabajos Fotogramétricos Aéreos (CEFTA), popularmente conocido como "vuelo Ruiz de Alda", cuyo interés radica en dos aspectos: la fecha en la que se realiza y la calidad de las imágenes obtenidas. En el ámbito de estudio, restringido al área de cuenca definida por la CHS, queda documentada la configuración del territorio a principios del siglo XX, con imágenes de una precisión aproximada de escala 1:10000 y una resolución de entre 0.3 y 0.5 metros por pixel (CHS, 1995). Este documento gráfico, encargado desde la necesidad de planificación de una infraestructura, supone un punto de partida único para comprender la evolución del territorio y la configuración del paisaje primigenio. A este primer vuelo le seguirán otros, distanciados en el tiempo y cuyo objeto de encargo no fue específicamente el estudio de la cuenca; no obstante, el estudio gráfico de la secuencia temporal permite establecer las pautas de cambio y relacionarlas con otros hechos históricos importantes en el contexto de la investigación.

En la figura 1 se muestra de manera sintética la cronología de la serie histórica de episodios de riadas más relevantes que afectaron al tramo de la Vega Baja, según las fuentes consultadas, junto con algunas reseñas a hechos históricos relacionados con ellos -columna izquierda-; así como los vuelos fotogramétricos consultados con el objetivo de reconstruir la evolución del territorio -columna derecha-, con los que la serie fotográfica nos permite obtener información precisa de carácter tanto cuantitativo como cualitativo. 


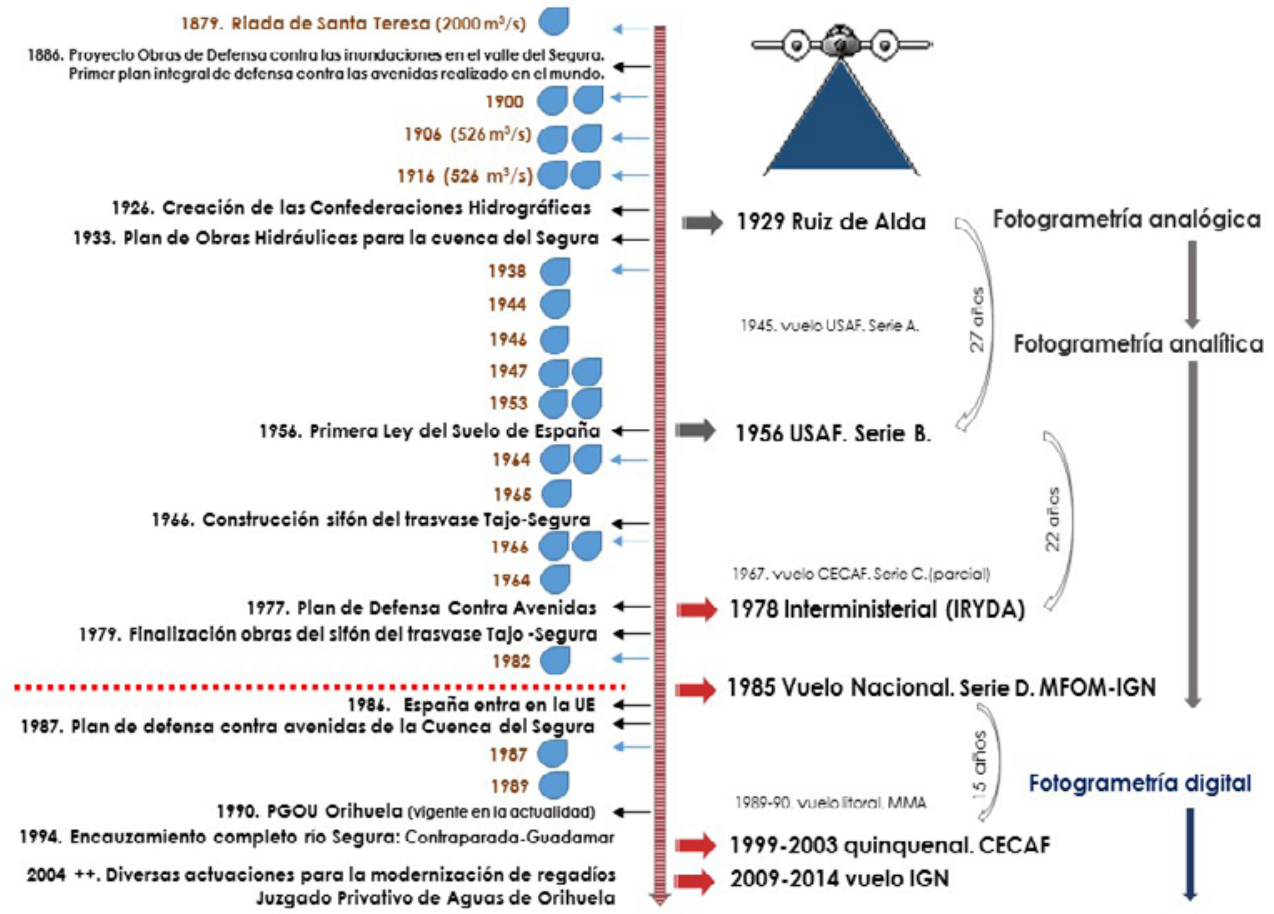

Fuente: Elaboración propia a partir de diversas fuentes: CHS; Gil y Morales, 2001; Vales, 2010; Vera y Lorenzo, 2011; JPAO, 2014 (web).Desbordamientos acaecidos el mismo año: 1 riada $\bigcirc$; 2 riadas $\bigcirc \bigcirc$;

A lo largo de un siglo de historia, este área ha sufrido cambios constantes pero a diferentes velocidades. A partir de la secuencia fotogramétrica histórica se ha constatado que, durante gran parte del siglo XX, hasta prácticamente los años noventa del mismo, la Huerta mantuvo un equilibrio, el paisaje fundamentalmente de tipo agrícola fue asumiendo cambios de manera progresiva, con una cadencia que permitía la asunción de las transformaciones con naturalidad por parte de la población local, ya que el carácter y la escala de las mismas estaba en consonancia con la cultura y la tradición. El ritmo de generación de tierras de cultivo y su consolidación como principal actividad local, mantenida durante diez siglos de historia, se vio rota en la última década del siglo $\mathrm{XX}$, periodo en el que destacan como factores influyentes: las circunstancias socioeconómicas con un cambio de modelo productivo; la legislación en materia de gestión de suelo, que facilitó la introducción de nuevos usos y una forma de ocupación diferente (Martí y Moreno, 2014); y, la tecnología, aplicada a diferentes niveles: riego, cultivos, caminos, entre otros, aceleraron la transformación de los entornos agrícolas tradicionales; y esta tendencia se ha mantenido hasta la actualidad. 
A través de las imágenes fotogramétricas queda documentado que entre 1929 (vuelo "Ruiz de Alda") - 1956 (vuelo “USAF") y 1977-83 (vuelo interministerial o del "IRYDA"), los cambios son mínimos y respetan la organización estructural tradicional del paisaje de Huerta de regadío: la geometría y distribución parcelaria se mantiene, se observan cambios en el incremento de arbolado productivo, pero todavía existe una hegemonía de las especies herbáceas y hortícolas de rotación. Es a partir de mediados de la década de los ochenta, y hasta el año 2000, cuando se aprecian variaciones que denotan cambios en los usos y costumbres de la población y, por tanto, en la construcción de un nuevo paisaje de Huerta. Se produce un incremento en la concentración de edificación en torno a los ejes tradicionales, se introducen nuevas tipologías de edificación, en la que el carácter básico de la vivienda del aparcero desaparece, para dar paso a casas de mayor volumen construido y diseñadas según los estándares de viviendas tipo urbano o bien segunda residencia contemporánea. Se ocupan parcelas tradicionalmente dedicadas a producción agrícola para nuevas actividades como almacenes o naves industriales con otros tipos de actividad comercial. Estos cambios se ven incentivados por la entrada de España en la UE y el efecto de cambio en la política agrícola; la puesta en marcha del Plan de defensa contra avenidas del río Segura, que supuso la rectificación de todos los meandros y espacios de retención del trazado del cauce, y una sustancial mejora en la capacidad de evacuación del mismo, con lo que las riadas con efectos devastadores van desapareciendo como preocupación principal en las nuevas generaciones y se relajan la actitud de la población hacia las condiciones de ocupación de suelo agrícola, flexibilizando la introducción de nuevos usos. Tal y como puede comprobar en la figura 1, tal y como estaba previsto con la rectificación del cauce, las crecidas del río no llegan a transformarse en avenidas catastróficas; pero tampoco existe el efecto positivo de fertilización, por aporte de los lodos del río a las tierras de huerto.

Esta tendencia, que se extiende y consolida a lo largo de toda la Vega Baja, se ilustra simplificadamente en la figura 2, donde sobre un mismo punto del valle, en este caso el cruce de la carretera de Beniel con la Vereda de la Buena Vida, perteneciente a la huerta de Orihuela, se muestran recortes de fotogramas de tres vuelos diferentes: el más antiguo, el vuelo de 1929; el vuelo Interministerial 1977-1983, como punto de inflexión y cambio en la evolución del paisaje de Huerta; y, por último, el vuelo del IGN de 2010, como imagen de la situación actual de esta zona.

Uno de los principales hechos constatables, a partir del estudio fotogramétrico, es que el paisaje de Huerta en el regadío tradicional ha permanecido prácticamente inmutable hasta finales de los años setenta y principios de la década de los ochenta, reflejado en el vuelo interministerial. Es a partir de esa fecha, a lo largo de las tres décadas siguientes, cuando se van sucediendo modificaciones que sí afectarán, no sólo a la fisionomía del paisaje, también en un nivel más profundo, a la forma de ocuparlo con nuevos usos y, por tanto, el establecimiento de una relación diferente entre la población local y el entorno huertano, distanciándose de los motivos que, en origen, promovieron la extensión y mantenimiento de la huerta productiva, prolongados durante diez siglos. 


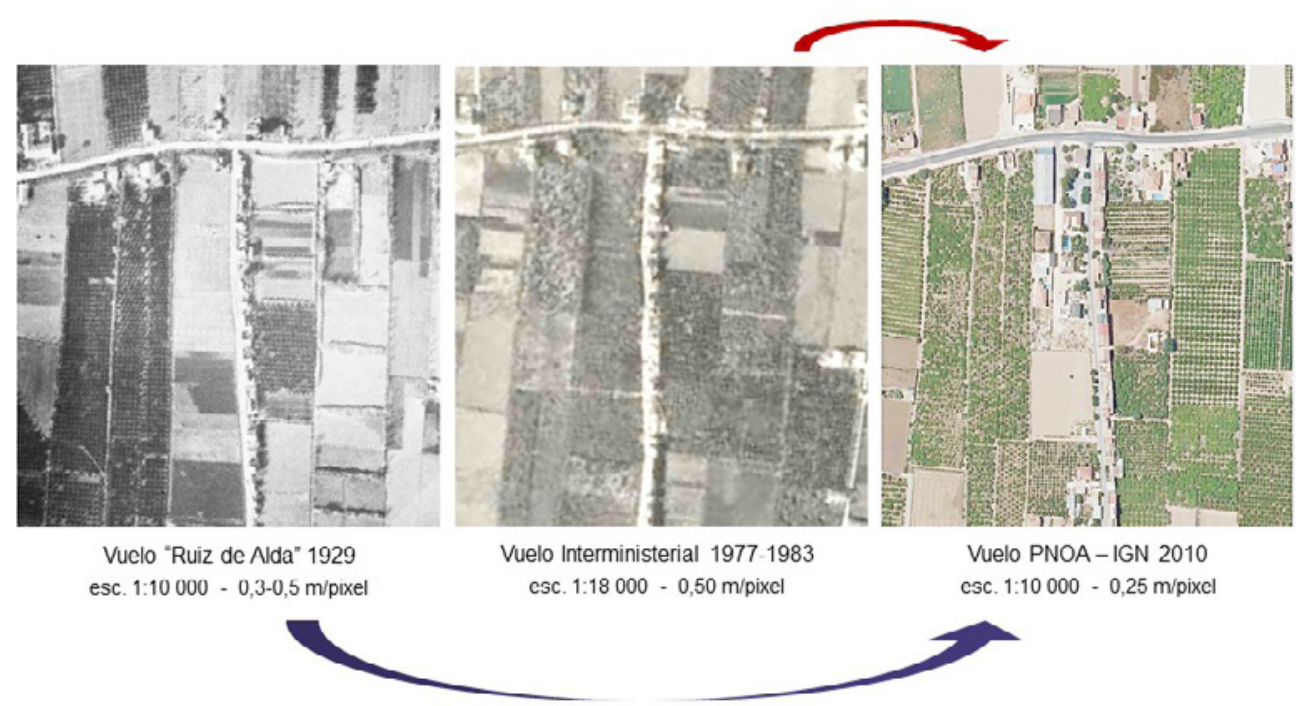

Fuente: elaboración propia a partir de recortes de fotogramas situados en el mismo punto georreferenciado, correspondientes a diferentes vuelos y años, indicados en cada imagen de referencia.

\section{LA MÉTRICA DEL TERRITORIO TRANSFORMADO: EVALUACIÓN DE INVARIANTES}

Los elementos que se han establecido como factores básicos e invariantes en la conformación de este paisaje de huerta son: en primer lugar, la red de riego-drenaje que es la que permitió en origen la transformación del suelo en parcelas productivas; en segundo lugar, pero interrelacionada con la anterior, la red de caminos, veredas o sendas, cuyo trazado discurre junto a los canales de agua; en tercer lugar, la naturaleza de los cultivos, de ciclo corto o bien arbóreos que, en función de su preeminencia han ido modificando la imagen productiva de la Huerta; y, por último, el hábitat construido, la ocupación y tipología así como el uso al que se destina. Estas piezas, que de manera separada conforman lo que denominaríamos armazón base de la identidad del paisaje, las distinguiremos globalmente como redes estructurantes del paisaje de la Huerta de la Vega Baja del Segura (García-Mayor y Canales, 2015).

Para poder evaluar los elementos que permanecen y mantienen la esencia estructural y formal del territorio frente a los que cambian; así como, determinar la repercusión de estas modificaciones en la interpretación del paisaje de Huerta, se utiliza un patrón de análisis a partir de la superposición de una retícula de 400 metros x 400 metros de paso sobre el área de estudio. Esta propuesta no es nueva, proviene de los mismos planteamientos que se utilizan en la parametrización de indicadores para contextos urbanos (AEU, 2008) (Rueda, 2008; 77-78). El argumento por el que se estima adecuada la implementación de esta metodología, 
pensada para un ecosistema urbano, a la escala territorial de carácter suburbano que es el ámbito de esta investigación, es el hecho de que, el modelo de trabajo es un sistema genérico de parametrización de la complejidad de la realidad física de una superficie. La propuesta de muestreo, para obtener una interpretación del escenario de evolución del área, es perfectamente adaptable y, una vez aplicada a un ámbito concreto y extraídas las primeras conclusiones, no hay duda de su eficacia para la investigación, su versatilidad y la oportunidad de aplicación a este caso.

Cada subdivisión de la malla, que denominaremos "tesela" puesto que conforma globalmente un mosaico territorial, se define por: su forma cuadrada, dada la simplicidad e isotropía, con la que es fácil establecer relaciones proporcionales a diferentes escalas; el tamaño -400 metros x 400 metros- es un área suficientemente representativa como muestra porque permite la valoración conjunta de una proporción elevada de tablas de huerta en relación al resto de elementos existentes en la zona; y, por último, la posibilidad de orientar y posicionar la tesela acomodada con respecto a los elementos estructurantes del paisaje, los caminos y los ejes de riego (figura 7).

El objetivo final trasciende la mera cuantificación de los crecimientos urbanos, o bien una revisión del incremento de las infraestructuras; para centrar la investigación en las relaciones existentes entre las transformaciones detectadas, la repercusión en la percepción del lugar y los cambios hallados en la relación de la sociedad con respecto al medio que habita. Por ello, la aplicación del método de análisis tiene como objeto el espacio agrícola propiamente dicho, que es el que históricamente ha caracterizado de manera singular este valle.

La relación de una sociedad con el medio en el que vive está absolutamente clara a través del análisis de la ocupación del suelo y de la tipología de las edificaciones construidas: emplazamiento, uso principal, diseño funcional y materiales. Aplicando esta premisa al caso de estudio que nos ocupa, comparando la situación de partida en el análisis del vuelo de 1929 respecto a la configuración actual de este mismo lugar, a través de las imágenes más recientes, se evidencia la evolución del territorio y se anticipa el resultado a corto plazo de las dinámicas territoriales sobre el paisaje y sus elementos identitarios.

\section{III.1. Caso de estudio: Vereda de la Buena Vida. Orihuela}

La elección del eje histórico de la Vereda de la Buena Vida (Figura 3), como caso de estudio que ilustre el método de trabajo utilizado, se fundamenta en diversos motivos. Por un lado, se trata de una vía de comunicación primigenia, perteneciente a una de las zonas de huerta de regadío más antiguas, tal y como se recoge en diferentes escritos y cartografías históricas (De Gea, 1997) (Canales y Segrelles, 2008). Perteneciente a la pedanía de Los Desamparados, esta vereda es uno de los recorridos iniciales de conexión del valle central, desde su entronque con la carretera a Beniel, con las tierras más elevadas del límite sur del mismo, cruzando transversalmente la llanura aluvial hasta la traza del antiguo camino a Cartagena. Por otro lado, la integración en el sistema huertano responde a la función de conexión, a la de accesibilidad a los predios y a la de permitir la construcción de un hábitat lineal a un lado del camino, estableciéndose así una relación directa entre lugar de vida - lugar de trabajo, que caracteriza globalmente estas aldea-calle con las que se fue colonizando la Huerta; ello nos lleva a adoptarlo como modelo representativo de hábitat huertano y su evolución. 


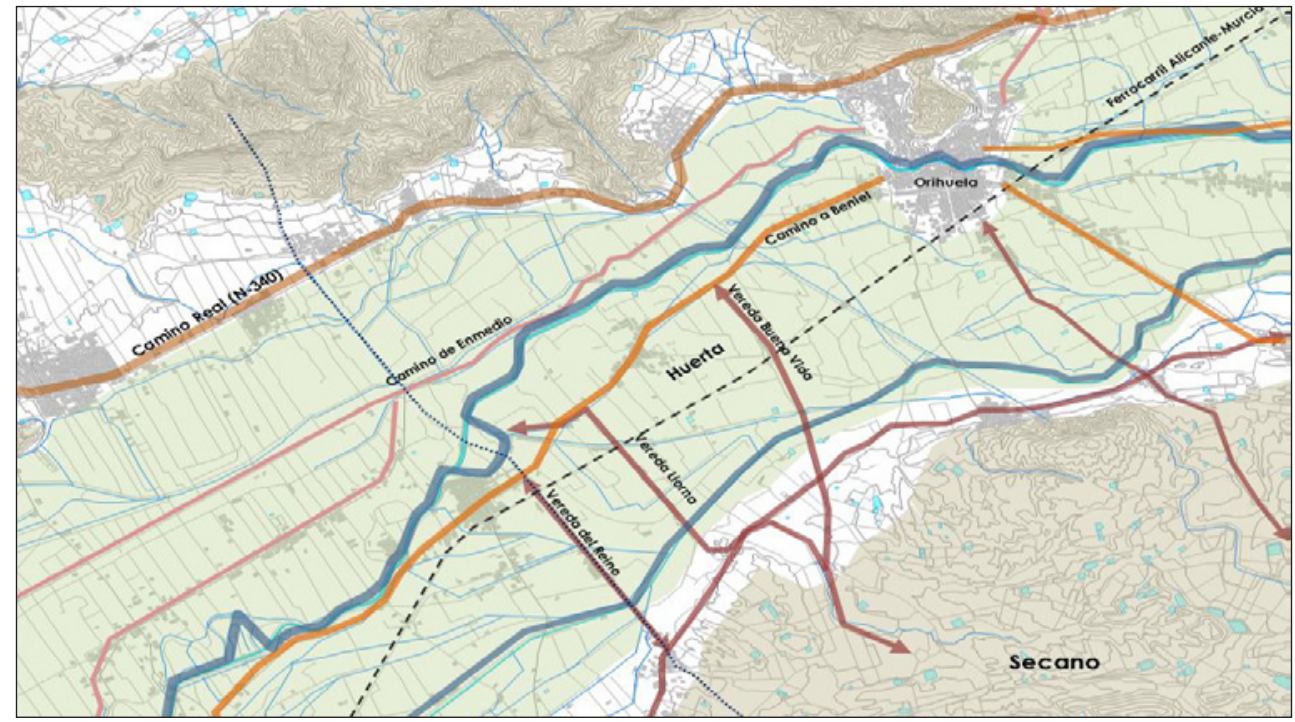

Fuente: elaboración propia. Principales ejes de la infraestructura de caminos tradicional en el área de la pedanía de Los Desamparados (Orihuela). La Vereda de la Buena Vida junto con la Vereda Liorna constituyen los caminos que "cosen" la Huerta de regadío tradicional en el centro de la llanura aluvial con las zonas más elevadas, dedicadas al cultivo de secano, hacia el límite sur del valle. En 1929 el punto de conexión entre la margen derecha y la izquierda del río, lo proporciona el puente del Molino de la ciudad. (Plano orientado al norte)

Centrándonos en el eje objeto de estudio, el territorio que muestran las imágenes del vuelo de Ruiz de Alda (figura 4 y figura 5) plasman un área agrícola, en la que las construcciones que se identifican con claridad tienen una escala pequeña, se trata de viviendas mínimas de jornaleros, asociadas a la actividad agrícola, pequeños almacenes de aperos o de cosechas con una estética similar a la de las viviendas procurando una ocupación mínima en planta, dándole la máxima prioridad al suelo productivo evitando la disminución de superficie de terreno fértil. Las edificaciones que conforman un modelo de alineación tipo "aldea calle", dispuestas en un único margen del camino, que incorporan especies arbóreas de copa amplia en el espacio exterior inmediato a las mismas. Esta vegetación relicta proporciona un lugar de sombra, a la vez que frutos para el consumo familiar o forraje para los animales domésticos, frente al acceso a la vivienda y a los huertos, brindando un espacio de actividad extensión del hábitat funcional para labores cotidianas, a la vez que adoptó así el papel del espacio público de relación para los vecinos de la zona. La calidad de definición del vuelo de 1929 permite la identificación de alineaciones de arbolado o bien ejemplares singulares, tanto por la dimensión de copa, como por la sombra proyectada. Esta particularidad, junto con la claridad de lectura del parcelario de huertas, permite identificar con seguridad la traza de canalizaciones de la infraestructura de riego-drenaje, o bien de la red de caminos principal, reforzada con la existencia de alineaciones de arbolado como hitos visuales en el paisaje de huerta. 
Figura 4

EVOLUCIÓN DEL PAISAJE DE HUERTA. CASO DE ESTUDIO: VEREDA DE LA BUENA VIDA. PEDANÍA DE LOS DESAMPARADOS. ORIHUELA
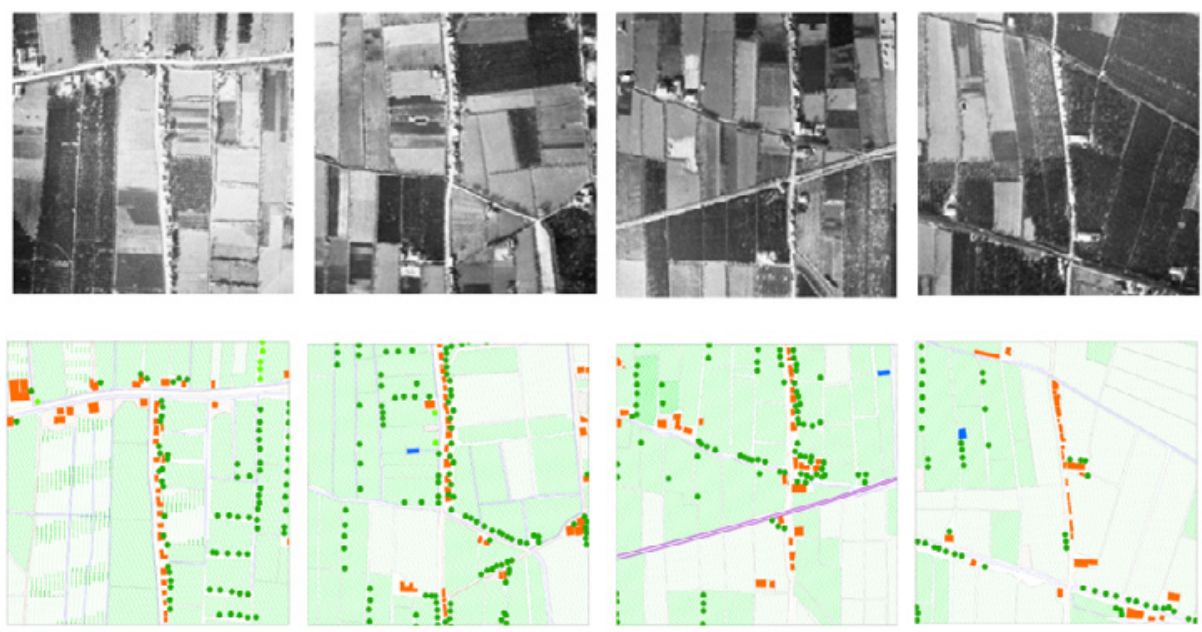

C1 -1929

C. .1929

C3.1929

C4-1925
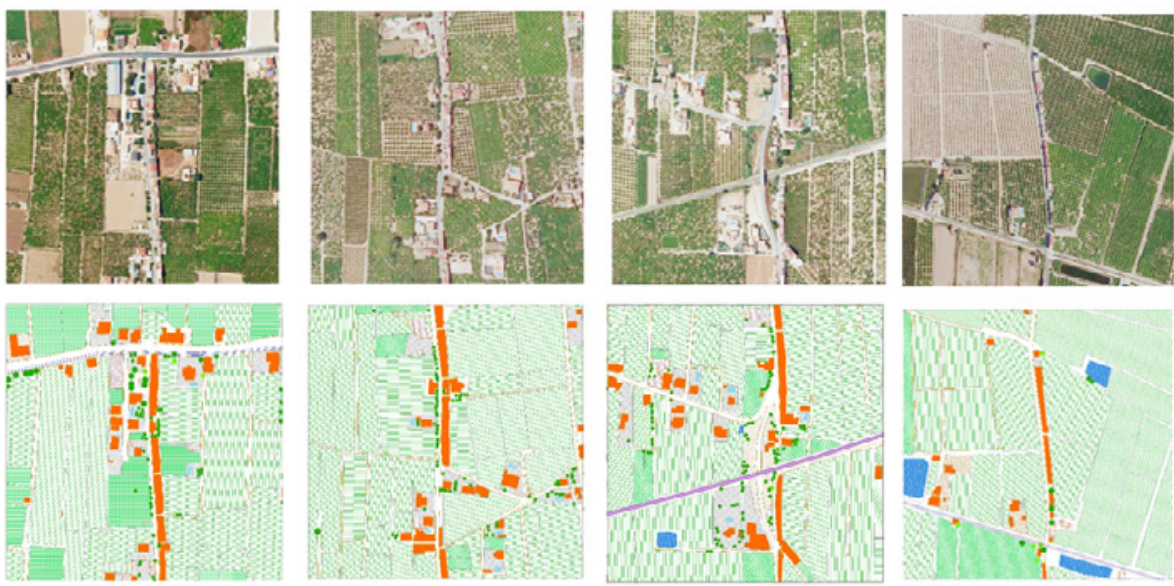

C1. 2010

C2. 2010

C.3. 2010

C. 2010

Vereda de la Buena Vida. Evaluación de la evolución del territorio a partir de la comparativa entre los años 1929 y 2010. Secuencia imágenes fila superior: recorte fotogramas del vuelo correspondiente al año de referencia. Secuencia gráficos fila inferior: Cartografías interpretativas de los elementos configuradores del espacio de Huerta dibujadas sobre la base del vuelo: construcciones, cultivos e infraestructuras. Fuente: Elaboración propia a partir de la información fotogramétrica de cada vuelo.

Si superponemos la información obtenida del análisis del vuelo de 1929, a la obtenida del vuelo de 2010, casi un siglo después encontramos un panorama bastante más transformado de lo que las cartografías interpretativas dibujadas parecen reflejar (figura 5). 
A través de la comparación de la huella del hábitat construido, comprobamos cómo la "aldea-calle" se ha densificado, las construcciones han perdido los espacios intersticiales de relación que existían, pasando a ser ocupados por las ampliaciones de vivienda, además de ampliarse el fondo edificado hacia los huertos traseros, perdiendo la vegetación relicta existente, con el objetivo de adaptarlas a las exigencias contemporáneas en cuanto a espacios y forma de vida más urbana. La ocupación de parcelas agrícolas se produce también al otro lado de la vereda, transformando de manera intermitente tablas completas de huerta productiva en parcelas urbanizadas. Las nuevas edificaciones también incorporan nuevos usos, por tanto, tipologías alejadas de las iniciales, tanto por escala, como por programa organizativo y requisitos funcionales: chalets residenciales con piscina y urbanización interior con ajardinamientos decorativos; naves industriales de actividad comercial en las que se utiliza la parcela exterior para acopiar materiales o como zona de aparcamiento; explanaciones improductivas dedicadas a almacenamiento auxiliar de maquinaria o materiales.

1929
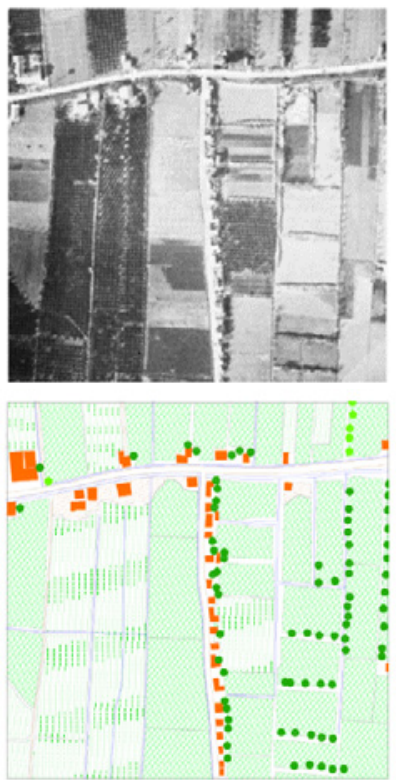

2010
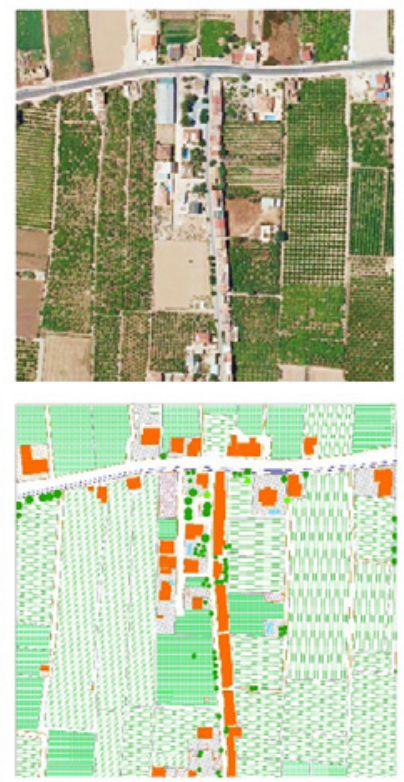

Cruce de la Vereda de la Buena Vida con el camino Orihuela (A) - Beniel (Mu). Evaluación de la evolución de una tesela de estudio a partir de la comparativa entre los años 1929 y 2010. arriba: recorte del fotograma del año indicado. abajo: Cartografías interpretativas. Fuentes: Vuelo 1929 Ruiz de Alda. Vuelo 2010 IGN. Cartografías: elaboración propia a partir de la información fotogramétrica de cada vuelo.

La Huerta de regadío tradicional en la Vega Baja del río Segura es un territorio en el que el tamaño de la parcela es relativamente pequeño como consecuencia de dos cuestiones: en primer lugar, el sistema de riego-drenaje utilizado está equilibrado en función de la capacidad 
de reparto y evacuación del agua, que viene determinada por la sección útil de los elementos de la red riego-avenamiento, la topografía y los tiempos de funcionamiento, así, el área de tabla de huerto regable, su geometría y las distancias máximas, está condicionada por criterios utilitaristas establecidos durante siglos de experiencia; en segundo lugar, la fertilidad de la tierra junto con la rotación de cultivos garantiza históricamente una productividad alta con varias cosechas al año según el caso, por lo que superficies relativamente pequeñas eran suficientes como módulo productivo. El mosaico y distribución parcelaria es una de las características que han permanecido más inmutable, otra cuestión diferente es el cambio de cultivo, de hortícola de rotación a arbóreo, o bien la introducción de nuevos usos, manteniendo la trama de teselas.

La figura 6 representa dos esquemas sintéticos detallados de transformación del primer tramo de la Vereda de la Buena Vida, desde el cruce con la carretera de Orihuela a Beniel (figura 5). Se identifica con claridad cómo entre 1929 y 2010 se pasa de una organización del hábitat siguiendo el patrón agrícola de "aldea-calle", a una expansión del modelo, con transformación del espacio de la vereda, en la que la vía de carácter agrario adquiere condición de calle urbanizada con edificación a ambos lados.
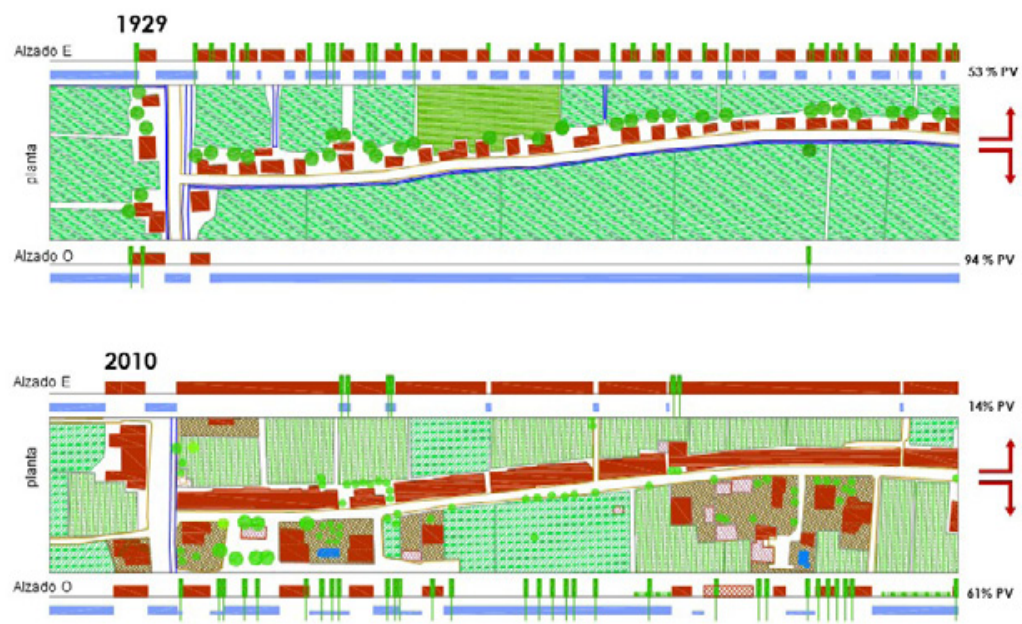

Cruce de la Vereda de la Buena Vida con el camino Orihuela (A) - Beniel (Mu). Evolución 1929-2010 de la ocupación de la edificación en las alineaciones de la vía. Para cada esquema de planta se representa en la parte superior e inferior sendos diagramas lineales: frentes edificados (rojo) y vegetación relicta (verde); permeabilidad visual (\%PV). Fuente: elaboración propia.

A partir de los esquemas de la figura 6, podemos comprobar cómo la experiencia del recorrido de la huerta a principios del siglo XX estaba totalmente relacionada con el medio de vida agrícola. Si nos fijamos en la evolución de la alineación este de la vereda, el hábitat lo conformaban construcciones independientes que, por proximidad, posición y tipología, generaban una percepción unitaria. Los espacios de separación entre edificaciones con dimensiones entre 1 metro y 7,7 metros, contribuían a tener una permeabilidad de algo más 
del 53\% sobre el tramo evaluado en el esquema. Estos lugares de actividad al aire libre, entre testeros, estaban protegidos por árboles de porte que ejercían de límite a la vez que generaban un interfaz de articulación de los huertos con el espacio de actividad doméstica cotidiana, asumiendo un papel de hito visual a lo largo de los recorridos.

La alineación oeste es un espacio totalmente abierto, 94\% de permeabilidad visual, donde la acequia de riego vinculada a la traza del camino, establece la delimitación de la tabla de huerta productiva. En un contexto en el que la producción agrícola estaba dedicada principalmente a cultivos de rotación, con un flujo habitual de braceros, las teselas de huerto eran un espacio cambiante en cuanto a texturas, colores, en el que el paso del tiempo estaba directamente relacionado con la estacionalidad y ciclo de las plantaciones, turnos de riego junto con el sonido del agua, la vinculación emocional y la interpretación del paisaje de huerta por parte de la población local y, por extensión, la foránea, tenía que ver con la dinámica y la actividad.

Si analizamos este mismo gráfico, con las condiciones que presenta el tramo de vereda en el siglo XXI, comprobamos cómo la desaparición de los espacios intersticiales reduce la permeabilidad visual en ambas márgenes del camino. De manera más drástica, al este del camino, en el que la alineación de casas se ha convertido en una fachada continua que ejerce de barrera, dejando en anecdóticos los puntos desde los que se pueden ver las huertas, un 14\% de huecos, repartidos en aperturas mínimas y constreñidas por una edificación que ha crecido en altura para adaptarse a las necesidades y expectativas en cuanto a residencia de la sociedad actual. Las ampliaciones en la ocupación de suelo de los edificios se realiza a costa de sacrificar el arbolado relicto, por tanto el interfaz permeable huertas-camino es prácticamente inexistente en el tramo estudiado. El margen oeste del mismo camino está sometido a un proceso de ocupación de los espacios alineados al camino, por tipologías edificatorias y usos diferentes de los tradicionales. Se aprecia cómo las construcciones están retranqueadas con respecto a los límites de una parcela vallada que sustituye el huerto por un acondicionamiento del terreno y ajardinamiento de características urbanas. Este hecho hace que, no sólo disminuya la permeabilidad visual en el tramo un 33\%; sino que hay un efecto adicional en la comprensión de este espacio, derivado de las características de volumen, forma y materiales de estas nuevas construcciones, destinadas tanto a residencia como a naves de almacenamiento o bien naves comerciales.

Con respecto a las transformaciones en el recorrido, hay que destacar un hecho que se extiende a toda la Huerta en esta zona: la traza de la acequia se oculta entubada bajo la ampliación de la anchura del vial para mejorar la sección útil de calzada y facilitar así la accesibilidad a los usuarios. Esta circunstancia origina la invisibilidad de la red de riego y, por tanto, ya no se pueden ver diferentes actividades y fenómenos asociados con la misma, como son: el flujo de paso de agua y la cadencia de las tandas o turnos de riego, la actividad de monda o limpieza de canales, el sonido de circulación del agua, el efecto de regulación higrotérmica por evapotranspiración en épocas de verano, la aparición de neblinas al amanecer y al anochecer, antaño características en todo el valle.

Por todo lo descrito, podemos afirmar que las transformaciones, que a continuación cuantificaremos en el tramo de estudio a modo de ejemplo, van más allá de lo visual e implican una experiencia sensorial diferente. Es en nuestros desplazamientos habituales desde donde confeccionamos la construcción mental de los lugares que vivimos o visitamos; por tanto, es desde la red de caminos desde donde aprehendemos la realidad, confeccionando la abstracción de los elementos esenciales que identifican un espacio, anclándolo a nuestras vivencias personales. 


\section{III.2. La métrica del paisaje transformado: cuantificación de los cambios y evaluación de invariantes}

A partir de la identificación de los elementos fundamentales que configuran el paisaje de Huerta: Huertos (cultivos arbóreos o herbáceos), Edificaciones, Red de caminos y Red de riego y Otros usos (improductivo, explanadas, infraestructuras), se ha cuantificado la proporción de cada uno de ellos sobre una serie de cuatro teselas (figura 7) del eje de la Vereda de la Buena Vida, en 1929 y en 2010, como muestreo.

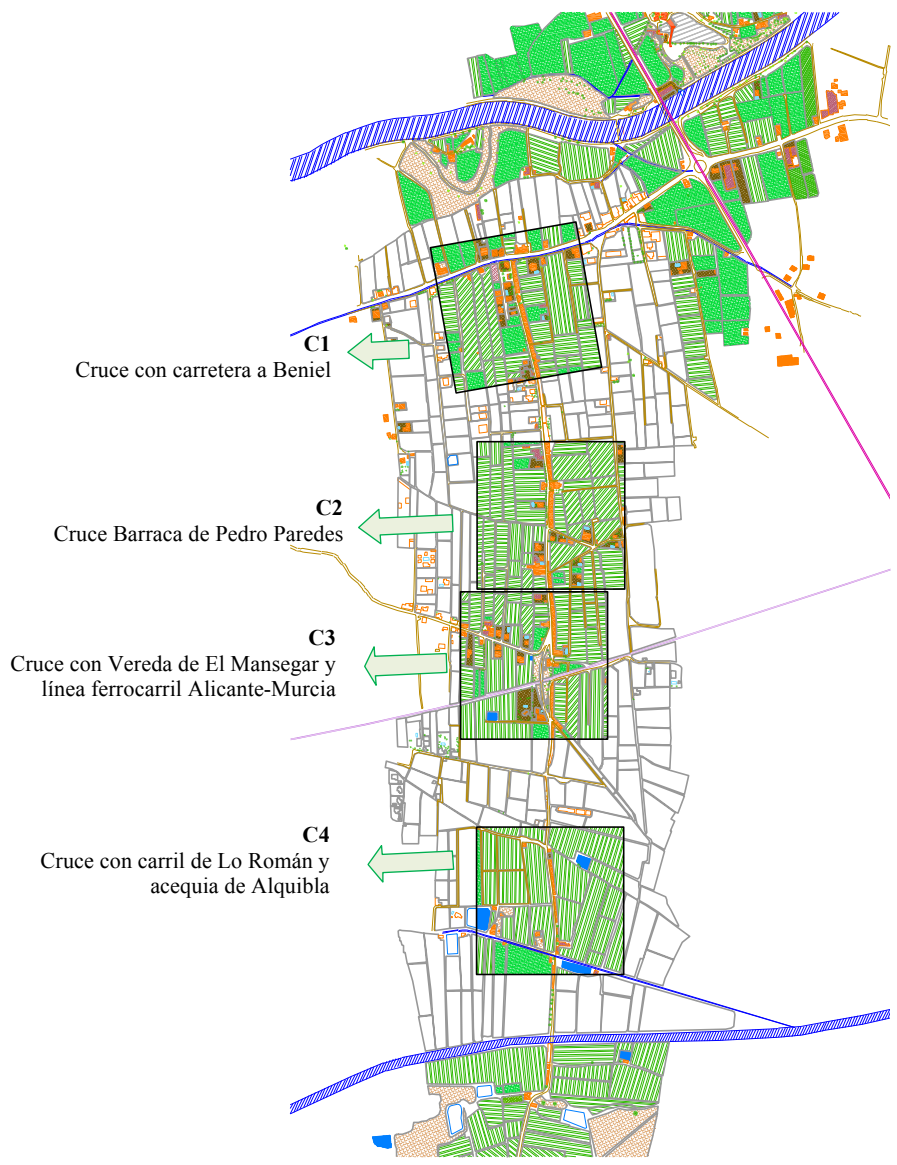

Distribución de teselas (cuadrantes) de estudio a lo largo del eje de la Vereda de la Buena Vida. C1-C2-C3-C4. Dimensiones del cuadro: 400 x 400 m. Superficie: 160000 m². Fuente: elaboración propia.

La figura 8 representa en un gráfico de barras los resultados de dicha cuantificación, de manera que se puede evaluar el proceso de cambio con cifras. 

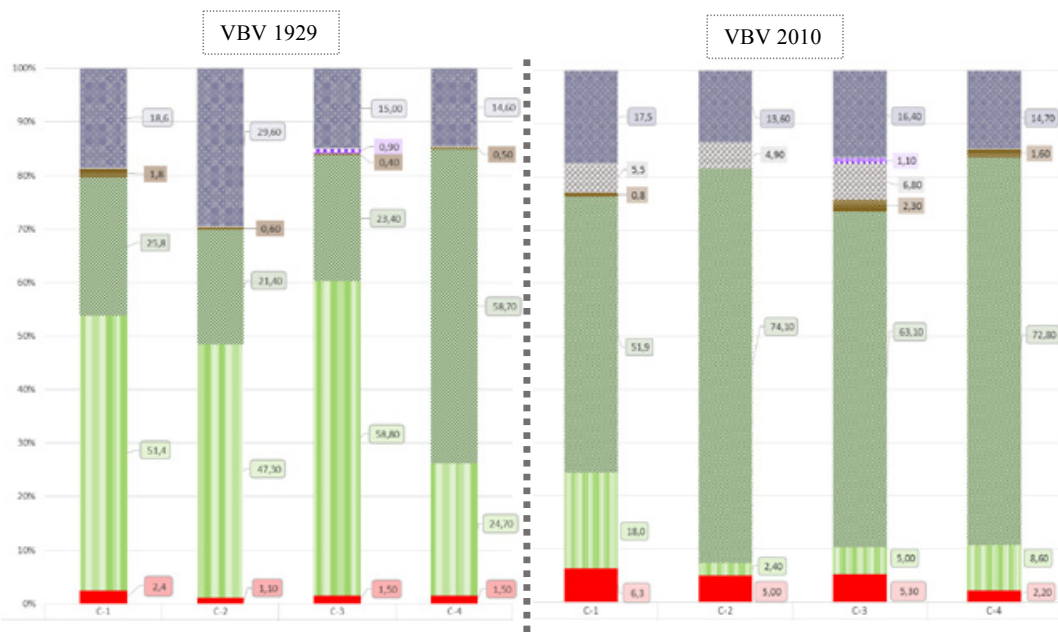

Estudio comparativo de los componentes principales del paisaje de Huerta de regadío tradicional en cuatro teselas seleccionadas a lo largo de la Vereda de la Buena Vida (VBV). Orihuela. Cada barra del gráfico cuantifica la proporción de elementos que componen la tesela correspondiente (C1-C2-C3-C4). La figura muestra los resultados obtenidos en el vuelo de 1929 y en el de 2010. Fuente: elaboración propia a partir del análisis de las imágenes de los vuelos de referencia.

\section{Edificación:}

Si atendemos a los valores referidos a la ocupación de la edificación en planta, vemos que en 1929 existe una cifra media en torno al 1.60\%, que son $2650 \mathrm{~m}^{2}$ de un total de 160 $000 \mathrm{~m}^{2}$ que abarca la superficie de una tesela de estudio. Esta cifra es más elevada en la primera tesela, que evalúa la zona de cruce entre la vereda y el camino a Beniel -otra de las arterias históricas de la Huerta-. Si cotejamos esta cifra con la ocupación en 2010, podemos comprobar como todos los valores se han incrementado, el que menos multiplicado vez y media, llegando hasta cuatro veces y media más que la tesela 2 (C-2). No se trata únicamente de cifras, sino de organización espacial y tipologías -residencias y naves comerciales- que, como ya se ha avanzado anteriormente, supone la ocupación de nuevas franjas de terreno a ambos lados del camino, modificando el patrón histórico y cambiando las relaciones visuales, además de introducir volumetrías y usos que transforman la esencia original del espacio huertano.

\section{Huertos:}

En cuanto a la superficie dedicada a terrenos de cultivo, si consideramos conjuntamente herbáceos y arbóreos, los porcentajes totales son similares entre 1929 y 2010; variando entre un $68.7 \%$ y el $83.4 \%$ de extensión a principios de siglo XX, y entre un $68.1 \%$ y el $81.4 \%$ en la primera década del siglo XXI. Aunque el área destinada a producción agrícola no cambia 
sustancialmente, sí lo hace el tipo de cultivo que predomina. En términos generales, los fotogramas del vuelo Ruiz de Alda muestran una Huerta dedicada a la rotación de cultivos herbáceos, que suponen más del 50\% de la superficie de las teselas excepto en el cuarto cuadrante, en el que son los cultivos arbóreos los que dominan; superficies entre los $75500 \mathrm{~m}^{2}$ y $\operatorname{los} 94000 \mathrm{~m}^{2}$.

Esta organización de las plantaciones se transforma absolutamente en la configuración actual de los huertos. Las cifras nos muestran cómo las tablas de huerta destinadas a cultivos herbáceos quedan relegadas claramente, pues en el mejor de los casos no ocupan más del $18 \%$ de la tesela estudiada, llegando incluso a un $2.4 \%$, cediendo espacio a favor de la plantación de cítricos fundamentalmente. Si analizamos las cifras con detalle comprobamos cómo la extensión de estos cultivos llega hasta un $74.1 \%$ del cuadro, unos $118000 \mathrm{~m}^{2}$ del total del $160000 \mathrm{~m}^{2}$ del área seleccionada. Este factor no es únicamente una cuestión de superficies incrementadas o bien transformadas, que sí lo es; pero, tal y como se ha puesto de manifiesto en el apartado anterior con el incremento de la ocupación por edificación, hay una modificación perceptiva del escenario del valle, que implica más factores igualmente relevantes.

Por un lado, el arbolado de cítricos incorpora un tapiz verde de carácter permanente, fundamentalmente en las visuales alejadas del centro del valle o en aquellos puntos de cota un poco más elevada. Ello puede tener una interpretación positiva desde la visión del verde continuo en una zona donde la aridez del territorio hace muy escasas las masas boscosas. Pero, por otro lado, el arbolado es una clara fachada que tapa las visuales de largo alcance a lo largo de los ejes que recorren el centro del valle. La frondosidad y altura de copa es un frente estático imperturbable, que construye un laberinto por la pérdida de referencias visuales. A este hecho se suma una cuestión adicional, el menoscabo de superficie de cultivo rotativo, que modifica las relaciones entre estacionalidad, cosecha y trabajo, disminuyendo las actividades dependientes de braceros y rebajando las relaciones entre medio agrícola y sociedad.

\section{Otros usos: improductivos, infraestructuras y explanadas:}

En cuanto a la organización espacial de los elementos de la Huerta, los espacios que se han etiquetado como "improductivos" aglutinan aquellas áreas que no pertenecen a la estructura de huertos cultivados: en 1929 son fundamentalmente cunetas y márgenes junto a las infraestructuras de caminos o riego; en 2010, se añaden a esta categoría taludes de infraestructuras y parcelas explanadas para el acopio de materiales, uso no regulado. Realmente supone una cifra anecdótica en el total de la estructura de una tesela, entre un $0.5 \%$ y un $1.8 \%$ a principios de siglo XX, para pasar a cifras entre el $1.7 \%$ y $9.1 \%$ en la actualidad. Los porcentajes más elevados tienen que ver con la tesela por la que discurre el corredor ferroviario, con una repercusión importante como cicatriz abierta en la Huerta (el presente estudio no recoge el impacto de la infraestructura correspondiente a la nueva línea de Alta Velocidad, actualmente en ejecución).

Volviendo al mismo razonamiento que en las categorías anteriores con respecto a la percepción del lugar: se trata de espacios baldíos que incrementan las áreas no utilizadas en la Huerta actual generando, en los lugares circundantes a los mismos, entornos de muy baja calidad paisajística y ambiental. 


\section{Caminos y red de riego-drenaje:}

El esqueleto estructural de todo el sistema de la Vega Baja del Segura está organizado en según las redes funcionales de flujos: agua y movilidad, tal y como ya se ha explicado. Para calcular la proporción de espacios vinculados a estas redes con respecto a la distribución total en las teselas, se ha optado por calcularlo de manera conjunta y como resto a partir del descuento de las superficies destinadas a los usos anteriormente descritos; se trata de una cuestión funcional, dado que el detalle fotográfico de los vuelos no permitía identificar y discriminar con la precisión necesaria los caminos de los ejes de riego, atendiendo además al hecho de que muchas de las acequias y azarbes han sido entubados, bien para protegerlos, bien para poder ampliar la sección útil de los propios caminos de acceso.

El dato más relevante es que las cifras son las mismas con variaciones despreciables, asumiendo el margen de error que puede existir en la restitución gráfica de los vuelos a la hora de trazar con absoluta precisión el límite de los caminos con respecto a los huertos o acequias. Podemos comprobar cómo en 1929 entre un $14.6 \%$ y un $18.6 \%$ de la superficie de la tesela son redes básicas de la Huerta; lo que corresponde con superficies entre $24000 \mathrm{~m}^{2}$ y casi $30000 \mathrm{~m}^{2}$ del total de $160000 \mathrm{~m}^{2}$ de cada cuadrante, salvo en la zona correspondiente al cruce con la Barraca Pedro Paredes (C-2) en la que la cifra aumenta hasta alrededor de los $47400 \mathrm{~m}^{2}$. Estas superficies se mantienen en 2010 entre el $13.6 \%$ y el $17.5 \%$.

Este constituye uno de los resultados más interesantes, en tanto cuantifica la proporción que tiene la red estructurante de este paisaje agrícola con respecto al resto de elementos que configuran su identidad. Además nos confirma la condición de invariabilidad dimensional de estos ejes como vectores de movilidad territorial y distribución del agua, cuya traza permanente ancla todos los estadios de su evolución hasta la actualidad.

\section{CONCLUSIONES}

El trabajo de análisis de la evolución de un territorio a través de la superposición de vuelos históricos no es algo novedoso; pero, en este caso, el poder disponer de fuentes de fotografía aérea de gran definición desde inicios del siglo XX, con el vuelo de Ruiz de Alda en 1929, tiene un gran valor documental que hasta la fecha no se ha utilizado de manera generalizada y sistemática, tal y como se plantea en esta investigación. La posibilidad de hacer un barrido temporal completo, desde estos primeros vuelos fotogramétricos hasta la información satélite o de fotografía digital georreferenciada, permite radiografiar con mucha precisión la manera en que el espacio de Huerta ha evolucionado. Una de las conclusiones principales que se extraen de este estudio es que la Huerta de regadío no sólo se ha mantenido, sino que ha ampliado continuamente su espacio de cultivo hasta prácticamente finales de los años ochenta o principios de los años noventa del siglo XX (Canales, 2012). Será el cambio de escenario económico, con un retroceso en la rentabilidad de la agricultura en favor de la economía basada en el desarrollo urbanístico y la construcción, lo que se traduce en una colonización de los huertos y la aparición paulatina de nuevos usos dispersos por el valle; desequilibrando, así, el sistema tradicional de cultivo, signo de identidad de la zona. Así mismo, han perdurado las líneas principales de estructura del tejido de Huerta: red de agua, caminos, tablas de cultivo; identificables y legibles hasta la 
actualidad, mantienen esa lectura de paisaje huertano descrita ya en los antiguos textos árabes, recogida y evocada a lo largo de los siglos por diferentes autores, estudiosos o artistas.

Además, para ir más allá del trabajo puramente descriptivo y poder avanzar parámetros cuantificables con respecto a la caracterización del espacio de Huerta, se han utilizado criterios adaptados del análisis del espacio urbano para el establecimiento de unos indicadores propios de la Huerta, que contribuyan, no solo a estimar y diagnosticar la evolución del paisaje, sino poder comparar con otras áreas de similares características. Con este sistema, se ha considerado el tamaño señalado de paso de retícula como medida óptima de tramificación del espacio de regadío tradicional para su medición. El objetivo final de esta fase del trabajo es establecer qué se percibe y en qué medida. Así, las conclusiones de este apartado nos permiten entender qué Huerta es la que la sociedad actual ve y de qué manera se ha transformado la identidad del lugar, en la que se evoca un paisaje imaginado perteneciente más al pasado que a la realidad del siglo XXI. No se trata de evaluar únicamente una cuestión estética o compositiva. En la medida en que los paisajes conforman el marco de relaciones y vida de una sociedad, condicionando su bienestar, resulta relevante y trascendente comprender la dinámica de los territorios y poder, así, anticipar las tendencias de cambio, al igual que identificar en qué medida éstos modifican el ADN del lugar.

Cruzar los datos de transformación del territorio a partir de la serie histórica de vuelos y asociarlos a la métrica de los invariantes del tapiz de Huerta, supone una aproximación a los detalles de interpretación del lugar que aúna la posición en el territorio y la escala física, de manera que las transformaciones en el paisaje adquieren dimensión espacial cuantificable, fundamental para evaluar las dinámicas que están incidiendo sobre un determinado lugar.

La Huerta representa un paisaje evolutivo y continuo en el tiempo, por cuanto es reflejo de la forma de vida tradicional de una comunidad a lo largo de su historia; y vivo, dado que sigue teniendo un papel activo en la sociedad actual. Así ha quedado registrado en obras de creación, tanto artísticas como literarias, al servir como fuente de inspiración constante para pintores, escritores y poetas, entre ellos, como figuras más destacadas del siglo XX, Joaquín Agrasot, Gabriel Miró y Miguel Hernández, cuyas composiciones pictóricas y literarias, inmortalizan una imagen huertana que permanece en la memoria colectiva de las personas. La vinculación del medio agrícola con la inspiración de carácter artístico, en la realización de obras que transcienden el carácter local, categoriza este paisaje de Huerta como paisaje asociativo siguiendo la terminología anterior; e incluso permite identificarlo según otros autores como paisaje lineal, al ser un claro exponente de una cultura de agua hereditaria, que se desarrolla a lo largo de los ejes de los ríos y también de las infraestructuras hidráulicas. La Vega es un entramado de canalizaciones que representa una obra monumental de este modelo, de estructura compleja, unida a factores significativos como son los sociales, económicos y tecnológicos, que han motivado unos principios de autenticidad, integridad y gestión racional (Rössler, 2002).

La identidad del paisaje está condicionada por la legibilidad y la coherencia de determinados elementos del mismo; por tanto, la pérdida de consistencia en lo formal determina una nueva identidad (Martínez de Pisón, 2010; Ponce, 2011). Al igual que una sociedad se adapta a los cambios propios de su evolución, el paisaje es expresión de la dinámica existente entre naturaleza y población que la habita; por este motivo, la valoración que se hace de un entorno, o la percepción por parte de sus habitantes, varía en función de los usos, la 
forma de vida y la modificación de las formas espaciales del lugar. Este cambio de percepción influye directamente en qué aspectos se estudian, protegen o gestionan, y ello establece, de nuevo, variaciones en el carácter del territorio (Antrop, 2005). En este sentido, la población perteneciente a la Huerta se ha transformado, las nuevas generaciones se han apoyado en opciones económicas alternativas, incorporando diferentes usos del suelo, alejados del agrícola, y enfocados al desarrollo de planes urbanísticos, la construcción y las empresas auxiliares a la misma. Hay una ruptura con la base cultural antigua, que modifica la dinámica de organización del suelo, tanto por la velocidad de los cambios, como por la escala de los elementos, incluyendo el distanciamiento respecto a los valores ancestrales que los propietarios de la tierra, así como las administraciones en general, evidencian en su toma de decisiones.

\section{BIBLIOGRAFÍA}

AGENCIA DE ECOLOGÍA URBANA DE BARCELONA (AEU, Barcelona) (2008): Plan Especial de Indicadores de Sostenibilidad Ambiental de la Actividad Urbanística de Sevilla. Barcelona. Anexo 01: Metodología definición malla de referencia, pp. 77-78.

ANDRÉS SARASA, J.L. (2011): El Neopaisaje de la Huerta de Murcia. Junta de Hacendados de la Huerta de Murcia. Murcia

ANTROP, M. (2005): "Why landscapes of the past are important for the future". Rural Landscapes: past processes and future strategies in Landscape and Urban Planning, 70 (1), pp. 21-34.

CALVO GARCIA-TORNEL, F. (1972): "La formación del paisaje agrario de la huerta de Murcia”. Revista de Geografía, no 6, pp. 5-33.

CANALES MARTÍNEZ, G. (2012): "La Huerta del Bajo Segura, paradigma de la Cultura del Agua”, en GÓMEZ ESPÍN, J.M. et al, Patrimonio Hidráulico y Cultura del Agua en el Mediterráneo. Murcia, Fundación Séneca, Agencia Española de Cooperación Internacional para el Desarrollo, pp. 265-287.

CANALES MARTÍNEZ, G. y SEGRELLES SERRANO, J.A. (2010): "Situación actual y perspectivas de futuro de un paisaje cultural: la huerta del Bajo Segura (Alicante)", XV Coloquio de Geografía Rural, Territorio, paisaje y patrimonio rural, Cáceres, Universidad de Extremadura, Asociación de Geógrafos Españoles, Cd.

CANALES MARTÍNEZ, G. (1993): "Modificaciones en las estructuras agrarias del Bajo Segura (1940-1990)", Medio siglo de cambios agrarios en España, Alicante, Instituto de Cultura Juan Gil-Albert, pp.485-517.

CANALES MARTÍNEZ, G. y otros (1995): “Territorio y Urbanismo en el Bajo Segura”. Alquibla, Revista de investigación del Bajo Segura, 1. pp. 173-204.

CHS (Confederación Hidrográfica del Segura) (1995): Encauzamiento del río Segura desde la contraparada (Murcia) hasta Guardamar del Segura (Alicante) y recuperación de sus sotos. Murcia. Ministerio de Obras Públicas, Transportes. Dirección General de Obras Hidráulicas.

DE GEA CALATAYUD, M. (1995): “La construcción del paisaje agrario del Bajo Segura. De los Orígenes hasta la implantación de la red de riego-drenaje principal en el alfoz oriolano". Alquibla, Revista de investigación del Bajo Segura, 1. pp. 65-101. 
DE GEA CALATAYUD, M. (1997): "La formación y expansión decisiva de la huerta de Murcia-Orihuela: Un enfoque desde la perspectiva de la Orihuela Musulmana (siglos VIII-XIII)". Alquibla, Revista de investigación del Bajo Segura, 3. pp. 155-217.

GARCÍA-MAYOR, C. y CANALES MARTÍNEZ, G. (2015): La Huerta de Orihuela en el Bajo Segura. Elementos funcionales en la construcción del paisaje. Cátedra Arzobispo Loaces. Universidad de Alicante.

GIL OLCINA, A. y MORALES GIL, A. (eds.) (2001): Insuficiencias hídricas y Plan Hidrológico Nacional. Murcia, CAM, Fundación Caja del Mediterráneo.

GÓMEZ ORDOÑEZ, J.L. y GRINDLAY MORENO, A.L. (Dirs.) (2008): Agua, Ingeniería y Territorio: La transformación de la cuenca del río Segura por la Ingeniería hidráulica. Murcia, Ministerio de Medio Ambiente, Medio Rural y Marino. Confederación Hidrográfica del Segura.

GRINDLAY MORENO, A.L. y HERNÁNDEZ GÓMEZ-ARBOLEYA, E. (2007): “Las infraestructuras hidráulicas en la cuenca del Segura”. Sevilla, Actas del V Congreso Nacional de la Ingeniería Civil: Desarrollo y sostenibilidad en el Marco de la Ingeniería.

JPAO (2014): Juzgado Privativo de Agua de Orihuela. Web (https://www.jpao.es/ fecha de acceso septiembre 2014)

MARTÍ CIRIQUIÁN, P. y MORENO VICENTE, E. (2014): "La transformación urbana y territorial de la ciudad de Murcia y su entorno (1977-2010)”. Estudios Geográficos, vol. LXXV, pp. 261-309.

MARTÍNEZ DE PISÓN, E. (2010): "Valores e identidades", en El paisaje: valores e identidades (Martínez de Pisón, E. y Ortega Cantero, N., Edits.). Madrid, Universidad Autónoma de Madrid, Fundación duques de Soria, pp. 11-45.

PONCE SÁNCHEZ, M.D. (2011): "Percepción de los procesos de urbanización y pérdida de paisajes identitarios en la Vega Baja del Río Segura" en Urbanismo expansivo, de la utopía a la realidad. XXII Congreso de Geógrafos Españoles. Universidad de Alicante, Alicante. pp. 555-566

RÖSSLER, M. (2002): "Los paisajes culturales y la Convención del Patrimonio Mundial Cultural y Natural: resultados de reuniones temáticas previas”, en Paisajes culturales en los Andes: memoria narrativa, casos de estudio, conclusiones y recomendaciones de la Reunión de expertos, Arequipa y Chivay, Perú, mayo de 1998. (Mújica Barreda, E., Ed.). Lima, UNESCO, p. 51.

RUEDA, S. (Dir.) (2008): Plan Especial de Indicadores de Sostenibilidad Ambiental de la Actividad Urbanística de Sevilla. Barcelona, Agencia de Ecología Urbana de Barcelona. Documento encargado por la Gerencia de Urbanismo del Ayuntamiento de Sevilla. pp. 77-78.

VALES, J.J. et al. (2010): "Producción de ortofotos históricas para la generación de bases de datos temáticas. Cartografía de usos y coberturas del suelo". REDIAM, en Ojeda, J., Pita, M.F. y Vallejo, I. (Eds), Tecnologías de la Información Geográfica: La información geográfica al servicio de los ciudadanos. Secretariado de Publicaciones de la Universidad de Sevilla. pp. 370-384.

VERA, J.A. y LORENZO, E. (2011): El Vuelo Americano de 1956 en la Cuenca del Segura: Proceso de elaboración de ortofotografía digital en las zonas de Albacete y Alicante. Murcia, Oficina de Planificación Hidrológica de la Confederación Hidrográfica del Segura. 


\section{Recursos electrónicos:}

CONFEDERACIÓN HIDROGRÁFICA DEL SEGURA (CHS). https://www.chsegura.es/ INSTITUTO GEOGRÁFICO NACIONAL (IGN). Ministerio de Fomento. www.ign.es 